\title{
A paridade de gênero nas sociedades e demais organizações privadas**\#
}

\author{
La paridad de género en las sociedades y demás organizaciones \\ privadas
}

\begin{abstract}
Patrícia A. Fernandez de Andreani ${ }^{1}$
Resumo: Não se pode negar que a desigualdade de gênero está presente em todas as relações sociais; a maioria dos espaços estratégicos de tomada de decisão são ocupados sob um sistema de desigualdade de gênero. Nesse sentido, o objetivo deste artigo é realizar uma análise jurídica sobre os avanços que foram feitos para alcançar a desejada paridade de gênero nos espaços de tomada de decisão. Por meio do método indutivo é possível concluir que é necessário trabalhar ainda mais em mecanismos legais que incluam de forma obrigatória a participação ativa das mulheres nos espaços de tomada de decisão corporativa que permitam alcançar não apenas a paridade de gênero, mas reduzir muito mais as lacunas da desigualdade social.
\end{abstract}

Palavras-chave: Igualdade de gênero. Direito societário. Liderança coporativa.

Resumen: No puede negarse que la desigualdad de género está presente en todas las relaciones sociales; la mayor parte de los espacios estratégicos de toma de decisiones se encuentran ocupadas bajo un sistema de desigualdad de género. En ese sentido, el objetivo de este documento es poder realizar un análisis jurídico sobre los avances que se han ido concretando a fin de alcanzar la anhelada paridad de género en los espacios de toma de decisiones, por medio del método inductivo, se logra concluir en que es necesario trabajar aún más en mecanismos jurídicos que incluyan de manera obligatoria la participación activa de las mujeres en los espacios de decisión y toma de decisiones corporativas que permitan alcanzar no solo la paridad de género, sino reducir mucho más las brechas de desigualdad social.

Palabras-clave: Paridad de género. Derecho de las sociedades. Liderazgo corporativo.

\footnotetext{
* Uma primeira versão deste texto foi publicada em espanhol na Revista de las Sociedades y Concursos, Fundación Fidas, Buenos Aires, mar. 2020.

\# O texto foi gentilmente traduzido pela Doutoranda Valéria Emília de Aquino, da UFG, e revisado pelo Dr. Thiago Paluma, professor da UFU.

1 Profesora de derecho de Sociedades en la Universidad de Buenos Aires (UBA) y del Doctorado en Derecho de la Universidad del Museo Social Argentino (UMSA). Doctora en Derecho por la Universidad de Valencia (España). Master en Derecho Empresario de la Universidad Austral (Argentina). Abogada en la Facultad de Derecho de la Universidad del Comahue (Argentina).
} 


\section{Introdução}

A desigualdade das mulheres em relação aos homens é vivenciada em todas as ordens de vida e em todas as esferas, porém, se agudiza notavelmente nas áreas de decisão entendidas pelo relatório The World Women $2015^{2}$ como áreas de poder (power) e tomada de decisão (decision making).

São necessárias normas que promovam a integração equitativa entre homens e mulheres nos órgãos de administração das sociedades comerciais e outras pessoas jurídicas. Em especial, para as sociedades que se desenvolvem no âmbito da oferta pública, a paridade no órgão de administração deve ser uma obrigação de resultado e imperativa.

As normas devem penetrar no seio das desigualdades, reconhecendo que a possibilidade de maternidade e a assunção do cuidado familiar são as razões da discriminação. De tal modo que devem ser adotadas normas que corrijam as situações de desigualdade que as mulheres vivenciam tanto na política, no trabalho, na educação, na saúde, nas forças armadas, na mídia, nas universidades, nos sindicatos, entre outros.

A igualdade efetiva entre homens e mulheres em todas as esferas e especialmente na matéria que nos une, as sociedades comerciais, onde o patriarcado é patrão e senhor, permitirá o progresso na justiça, na dignidade e contribuirá para uma maior produtividade.

\section{A paridade democrática como primeiro passo para alcançar a paridade em outras organizações}

María Teresa Fernández de la Vega disse acertadamente que "a igualdade é o maior fator de transformação política, econômica e social" e acrescentou "sem democracia não há igualdade, mas sem igualdade não há democracia" (FERNÁNDEZ, 2018, p.37) . Atualmente, não se concebe a

\footnotetext{
${ }^{2} \mathrm{O}$ informe encontra-se disponível em: http://unstats.un.org/unsd/gender/worldwoman.html (acesso em 14 jun. 2020).
} 
democracia sem que ela seja paritária. Isso porque a igualdade formal e real entre homens e mulheres é um direito humano fundamental.

A igualdade é uma exigência da democracia atual e a subrepresentação das mulheres constitui um déficit democrático ${ }^{3}$. De forma que as normas devem nivelar as desigualdades existentes que impedem as mulheres de alcançar os âmbitos sociais e políticos relevantes, criando ao mesmo tempo uma consciência coletiva de igualdade.

A Argentina fez mérito na matéria, mas ainda não conseguiu penetrar nas desigualdades estruturais de gênero, mas avançou nesse sentido. O primeiro passo que permitiu aumentar a participação das mulheres foi a promulgação, em 1991, da Lei 24012, que estabeleceu um piso mínimo para a representação de mulheres nas listas partidárias para cargos nos Poderes Legislativos Nacionais. As mesmas deveriam ser compostas de pelo menos $30 \%$ de mulheres.

No entanto, a cota colocaria um limite no acesso das mulheres às câmaras legislativas. O Observatório de Política Eleitoral da Argentina, destaca que "a cota permitiu não só aumentar o número de mulheres nas cadeiras de nosso congresso, mas também ampliar a agenda parlamentar incorporando um conjunto de questões antes negligenciadas por um poder legislativo quase totalmente masculino".

Assim, destaca-se que a inclusão da mulher no processo deliberativo e decisório permitiu incorporar no debate perspectivas sociais silenciadas e feminilizar a agenda. Esse processo de participação das mulheres resultou na promulgação da Lei 27.412 em 2017, que estabeleceu a paridade de ambos os gêneros para as listas de cargos eletivos e partidários. Assim, se produziu um salto qualitativo na promoção dos direitos das mulheres ao aumentar a demanda de participação feminina de $33 \%$ para $50 \%$.

\footnotetext{
${ }^{3}$ Cfr. Plano de trabalho para a igualdade entre homens y mulheres da União Europeia 2006/2010 (UE, 2006 p. 275).
} 
O quadro jurídico que a Argentina alcançou se baseia nos termos do artigo 37 da Carta Fundamental que garante o pleno exercício dos direitos políticos, o qual se interpreta como permitindo medidas de ação positiva para garantir uma real igualdade de oportunidades entre homens e mulheres. Por sua vez, o art. 75 inc 23 estabelece que cabe ao Congresso legislar e promover medidas de ação positiva que garantam igualdade real de oportunidades e tratamento.

Também deve-se ter em mente que a Convenção para a Erradicação de todas as formas de Discriminação contra a Mulher (CEDAW, na sigla em inglês) possui uma hierarquia constitucional. No entanto, entendemos que a paridade de gênero deve ser constitucionalizada, assim como a promoção da efetiva realização da igualdade entre mulheres e homens.

Nesse sentido, a constituição portuguesa, bem como a alemã, se readequou, estabelecendo a primeira no seu art. 109 que "A participação direta e ativa de homens e mulheres na vida política é condição e instrumento fundamental para a consolidação do sistema democrático, devendo a lei promover a igualdade no exercício dos direitos civis e políticos e a não discriminação em razão do sexo no acesso a cargos públicos”. Por sua vez, a segunda no art. 3 dispõe que "Todas as pessoas são iguais perante a lei. Homens e mulheres gozam dos mesmos direitos. O Estado fomentará a efetiva realização da igualdade entre homens e mulheres (...)”.

A constitucionalização da paridade democrática e a promoção da igualdade efetiva entre mulheres e homens permitiriam que a igualdade permeasse todas as organizações, tais como as forças armadas, as forças de segurança, os meios de comunicação, a autoridade audiovisual, os sindicatos, as universidades, as pessoas jurídicas em geral e particularmente as sociedades comerciais.

A participação de mulheres e homens, tanto na economia, como nas áreas da vida social, cultural e civil, permitirá desmontar as bases da 
democracia patriarcal que impedem a concretização de uma sociedade igualitária (SEVILHA, 2018, p. 437).

Com isso se alcançaria o reconhecimento de mulheres e homens como sujeitos equiparáveis, eliminando o estereótipo que restringe as mulheres das mais variadas formas de organização política (da polis grega à república romana ou aos feudos ou reinos) e econômica (escravidão, feudalismo, mercantilismo) a nível doméstico, sob o poder do homem. É justamente esse estereótipo e a confirmação de que a discriminação é produzida pela capacidade de ser mãe e a assunção de obrigações familiares que consolida uma imagem de mulher pejorativa como objeto para, mais do que como sujeito com.

\section{Paridade democrática como primeiro passo para alcançar a paridade nas demais organizações}

Mesmo quando pensamos que não há área ou território em que as mulheres não estejam em desigualdade com os homens, não há dúvida de que o poder econômico e empresarial é um dos últimos e mais resistentes bastiões do patriarcado (SENET, 2018, p. 886). A propósito, é uma área onde a discriminação contra as mulheres é palpável.

Agora, como deveria ser o ambiente empresarial privado para que respeite a igualdade entre homens e mulheres? Em princípio, se concebe que a paridade deva ser promovida nos órgãos administrativos das pessoas jurídicas. Com o objetivo de promover ações positivas que permitam às mulheres o acesso aos diferentes espaços de liderança social, o direito comparado vem introduzindo normas que promovem esse fim nas sociedades.

Assim, a lei espanhola já em 2007 sancionou a Lei Orgânica 3/2007, de 22 de março, para a igualdade efetiva entre mulheres e homens. Em seu art. 75 relativo à responsabilidade social das empresas dispõe que "As sociedades obrigadas a prestar conta de perdas e lucros completa devem 
envidar esforços para incluir um número de mulheres em seu Conselho de Administração que permita alcançar uma presença equilibrada de mulheres e homens no prazo de oito anos a partir da entrada em vigor desta Lei. O disposto no parágrafo anterior será levado em consideração nas nomeações efetuadas na medida em que vença o mandato dos administradores designados antes do termo da entrada em vigor desta Lei.

Esta regra, de difícil interpretação, concebe a promoção da igualdade entre homens e mulheres como uma vertente da responsabilidade social empresarial, garantindo a presença equilibrada de homens e mulheres nos "conselhos de administração das sociedades comerciais" (HUERTA, 2009, p. 290).

$\mathrm{Na}$ doutrina, discute-se se esta regra alcança a todas as sociedades mercantis, uma vez que nem todas as sociedades mercantis são obrigadas a prestar contas de perdas e lucros completas ou as de capital e, dentro delas, aquelas de dimensão econômica significativa, também se discute se trata-se de uma simples recomendação isenta de sanções ou se trata-se de uma obrigação de resultados (IRUJO, 2010).

Esclarecemos que o "Código Unificado de Governança Corporativa" (ou Código Conthe), adotado pela Comissão Nacional do Mercado de Valores Mobiliários em 19 de maio de 2006, havia contemplado em uma das seções a recomendação para maior presença feminina. nos Conselhos de Administração das sociedades listadas na Bolsa.

Por sua vez, a Lei das Sociedades de Capital possui normas que buscam promover a igualdade de representação de gênero. Assim, o artigo 529 bis 2, "Caráter necessário do conselho de administração. 1. As sociedades cotadas deverão ser administradas por um conselho de administração. 2. O conselho de administração deverá zelar para que os processos de seleção dos seus membros favoreçam a diversidade de gênero, experiência e conhecimento e não soframm de vieses implícitos que possam implicar qualquer discriminação e, em particular, que facilitem a seleção de 
conselheiras.

Neste sentido, a mesma regra do artigo 529 quindecies 3 (b) dispõe " 3 . Sem prejuízo das demais funções que lhe são atribuídas por lei, pelo estatuto sociais ou, nos termos destes, pelo regulamento do Conselho de Administração, a Comissão de Nomeações e Remunerações terá, pelo menos, as seguintes funções: (...) (b) Estabelecer um objetivo de representação para o sexo menos representado no Conselho de Administração e elaborar diretrizes sobre como atingir esse objetivo".

Por fim, a Lei de Modificações Estruturais exige que o sócio seja informado sobre o impacto de gênero no órgão administrativo nos casos de transformação (art. $9^{\circ}$ ) e fusão (art. 31, 11).

Ainda que as normas abordadas em muitos casos consistam em recomendações ou soft low, visto que parece que os direitos das mulheres terminam na esfera privada, cedendo à "autonomia da vontade" de quem exerce atividade económica já que não se poderia obrigar as empresas a respeitar a igualdade de gênero na composição do órgão administrativo, sem afetar o princípio da livre iniciativa, que no direito espanhol está incorporado na Carta Fundamental (art. 38), a ideia é promover por meio desse tipo de diretriz que as sociedades disponham de um Regulamento do Conselho de Administração (LOBILLO, 2009, p.279-292; LAGUILLO, 2007; UGUINA, 2007, p. 441-443; MENDIZÁBAL, 2010, p. 1248) onde incorporem tais extremos, para evitar o uso alternativo do direito (GARCÍA DE ENTERRÍA, 2007, p.685-686).

No entanto, a União Europeia em 2012 avaliou que as medidas não vinculativas, especialmente as listadas, não atingiram o objetivo de aumentar a igualdade de gênero nas empresas em toda a União, exceto nos países que introduziram medidas imperativas e tal foi resolvido através da Proposta de Diretiva do Parlamento Europeu que visa melhorar o equilíbrio de gênero nos administradores não executivos das sociedades cotadas.

Assim, propõe-se o objetivo mínimo de uma presença de $40 \%$ do 
gênero menos representado entre os administradores não executivos das sociedades cotadas e exigindo que as empresas que tenham uma proporção menor de gênero menos representado entre os administradores não executivos que introduzam critérios nos procedimentos de seleção para atingir o objetivo mencionado. Esta exigência baseia-se na sociedade cotada devido à sua maior visibilidade e ao seu caráter de modelo de boa governança para as demais empresas que não atuam em bolsa. O prazo para chegar a esse percentual foi estabelecido até $1^{\circ}$ de janeiro de 2020.

Com foco na Argentina, advertimos que a Resolução Geral da Comissão de Valores Mobiliários que reforma o Código de Governança Corporativa de 14 de junho de 2019 estabelece como princípio que a diretoria deverá contar com níveis adequados de independência e diversidade que lhe permitam tomar decisões em prol do melhor interesse da empresa, evitando o pensamento em grupo e a tomada de decisões por indivíduos ou grupos dominantes dentro da Diretoria.

Em particular, a resolução indica que "A diretoria deverá promover ativamente a criação de uma diretoria diversificada, levando em consideração a diversidade de gênero, origem geográfica, idade, perfil étnico e experiência profissional ... Enquanto a diversidade de gênero, resulta de especial relevância para a empresa não somente considerando a composição da Diretoria sem a equidade na remuneração de seus membros como também a possibilidade de mulheres terem acesso a cargos de liderança no Conselho, como a Presidência do órgão ou algum de seus Comitês A transparência e a divulgação da diversidade na Diretoria é um elemento importante para os investidores e mostra a profissionalização do órgão.

Tem-se afirmado a respeito do interesse dos investidores pela igualdade de gênero que aumentou a conscientização sobre a representação das mulheres na liderança corporativa, a assunção de um papel mais ativo no próprio investimento, maior disponibilidade de produtos de investimento voltados para gênero, maior influência das mulheres na prosperidade 
econômica, maior expectativa de que os investidores respeitem os direitos humanos em suas operações básicas e em suas relações comerciais (MONTENEGRO, 2006; LANUS, 2018, p.13).

Conforme consta da reforma do Código de Governo Societário, apenas contém recomendações sobre a composição diversa do órgão de administração. Isso sugere que é difícil mudar a matriz masculina na gestão das sociedades que participam de oferta pública na Argentina, onde se constatou que 50\% das que se desenvolvem nesta área não contam com membros do sexo feminino em seus conselhos, enquanto que nos 50\% restantes há baixíssima participação feminina (CASAS, 2019).

No que se refere às sociedades fechadas, a lei geral das sociedades nada contém sobre regras que promovam a integração equitativa do órgão de administração. Aspiramos que uma regra neste sentido não seja uma mera recomendação, mas sim uma obrigação de meios onde se estabeleçam passos para alcançar uma integração efetiva de ambos os sexos. No que diz respeito às sociedades cooperativas, em 2016 foi conseguida foi parcialmente aprovado na Câmara dos Deputados da Nação de um projeto que promove a participação das mulheres ${ }^{4}$.

Com efeito, de acordo com o referido projeto, a Lei das Cooperativas seria modificada em seus arts. 50, 63 e 65. O Artigo 50 apresenta que quando o número de associados exceder cinco mil, a assembleia será constituída por delegados eleitos nas assembleias distritais eleitorais nas condições fixadas no estatuto e regulamento. Pode ser estabelecida divisão dos distritos em seç̧ões de forma a facilitar o exercício dos direitos eleitorais dos associados. Nestes casos a integração dos delegados deve assegurar a participação proporcional das mulheres de acordo com a composição do padrão de associados.

\footnotetext{
${ }^{4}$ Cfr. Projeto de Lei n ${ }^{0}$ 0904-D-2016, com aprovação parcial obtida na Honorável Câmara de Deputados da Nação Argentina na data de 23 nov. 2016.
} 
Já o Artigo 63 expressa que o Conselho de Administração será eleito pela Assembleia com a periodicidade, forma e número previstos no estatuto. Os conselheiros devem ser associados e não menos que três. A duração do cargo de diretor não pode exceder três exercícios. Os conselheiros são reelegíveis, a menos que expressamente proibido pelo estatuto. A representação feminina nos órgãos de administração será de no mínimo 30\% (trinta por cento). Caso o número de associadas seja inferior ao número de mulheres membros do conselho que resultar da aplicação desse percentual à sua composição, será estabelecida a participação obrigatória de uma mulher na integração do órgão de administração da cooperativa.Diante da impossibilidade de realização da integração obrigatória de uma mulher, a entidade cooperativa deverá informar a autoridade executora que decidirá justificadamente.

Quando o sistema eleitoral é por listas, sua composição deve manter a ordem alternada de uma e outra de pessoas de sexos diferentes até que seja cumprido o percentual estabelecido, não podendo ser oficializada nenhuma que não atenda a este requisito. Em todos os demais mecanismos eletivos de conselheiros, deve-se respeitar o percentual indicado no parágrafo anterior. Ficam dispensadas do cumprimento deste regime de representação mista as cooperativas constituídas exclusivamente por associados do mesmo gênero, cooperativas de grau superior e as constituídas exclusivamente por pessoas jurídicas. Nestes casos, comitês de igualdade de gênero devem ser estabelecidos para garantir a promoção e a participação equitativa de gênero entre seus associados.

Como se depreende do Projeto de Lei, que foi parcialmente aprovado pela Câmara dos Deputados, a obrigação de representar as mulheres não era mera recomendação, mas tratava-se de obrigação de resultado, uma vez que o descumprimento do mandato poderia ser observado pela Autoridade de Execução (INAES) e/ou impugnado de nulidade (art. 62 da Lei das Cooperativas). 
Recentemente, outro projeto de reforma da Lei 20.337 obteve aprovação parcial na Câmara dos Deputados, desta vez buscando estabelecer a paridade de gênero por meio do estabelecimento de uma composição igualitária entre homens e mulheres nos órgãos de administração cooperativa ${ }^{5}$.

As cooperativas são em si mesmas organizações voluntárias que, pelos seus princípios e natureza, se destacam pela maior integração e participação dos seus componentes, sem distinção de sexo, idade, religião, raça, etc. Portanto, é importante que a norma e os estatutos sociais incluam dispositivos que estabeleçam a integração eqüitativa de homens e mulheres.

\section{Conclusão}

Acreditamos que a Argentina merece um debate sobre a paridade em todos os espaços políticos e sociais, que permita sensibilizar e projetar uma construção plural, enriquecida por perspectivas conjuntas masculinas e femininas.

Em matéria de sociedades, consideramos conveniente pensar em uma regra que imponha uma obrigação imperativa para as sociedades que participam no âmbito de oferta pública, uma vez que possuem um número maior de conselheiros e são um modelo de boa governança para aquelas que não atuam na área da oferta pública. Por outro lado, para as sociedades fechadas consideramos conveniente que a obrigação seja de meio, onde se preconiza que os órgãos administrativos sejam constituídos por uma participação equilibrada de homens e mulheres.

Como apontado anteriormente, sabe-se que a origem das

\footnotetext{
5 Cfr. Projeto de Lei sob o processo $\mathrm{n}^{0}$ 0321-D-2019, com aprovação parcial obtido na Honorável Câmara dos Deputados da Nação Argentina em 20/11/2019. Nele fica estabelecido: "Artigo 10: Substituir o artigo 63 da Lei 20.337 da Lei das Cooperativas, que passará a ter a seguinte redação:" Conselho de Administração. Eleição. Composição. Artigo 63: "Fica eleito o Conselho de Administração pela assembleia com a periodicidade, forma e número previstos no estatuto. Os administradores devem ser associados, sendo compostos igualmente por homens e mulheres e não inferior a três membros".
} 
desigualdades e da discriminação contra a mulher está centrada na capacidade de ser mãe e cuidar da família, dos filhos e do idoso, ou seja, no estereótipo construído socialmente. Por isso, também é necessário abordar leis que trespassem a cultura e conscientizem sobre a corresponsabilidade nas obrigações domésticas.

Quando o presidente cessante Mauricio Macri abriu a agenda sobre a descriminalização do aborto e sua legalização na Argentina, ele surpreendeu moradores e estrangeiros, pensou-se que uma agenda feminista finalmente chegaria. No entanto, não foi. (BACCARO, 2009) Por sua vez, não foi discutido o projeto de igualdade salarial e também não foi aceito o projeto que estendia a licença-paternidade de dois dias para quinze dias. Essa não é uma questão menor, pois a promoção de uma maior corresponsabilidade entre homens e mulheres na assunção das obrigações familiares se constrói desde o nascimento do filho.

Esperemos que os novos tempos políticos na Argentina, que será liderado pelo presidente eleito, Alberto Fernández, venha a abordar a questão da discriminação estrutural contra as mulheres, que começa por aceitar que são elas que assumem o trabalho doméstico, caso contrário, será difícil concretizar a paridade social desejada.

Por certo, as mulheres não têm apenas o objetivo de alcançar uma paridade real em todas as áreas da vida pública, como a social, mas também temos desafios importantes, como a prevenção da violência de gênero, assédio, educação sexualidade integral, entre outras, mas boa parte dessas questões pode ser melhor abordada se quem lidera os espaços de forma equilibrada são as mulheres, juntamente com os homens.

\section{Referências}

BACCARO, D., La parábola macrista del aborto, un viaje de inicio y final inesperados. Clarín, Buenos Aires, 23 nov. 2019.

CASAS, Ximena. La mitad de las empresas que cotizan en la Bolsa porteña no tienen ninguna mujer en sus directorios. Infobae, 12 mar. 2019. Disponible en: 
https://www.infobae.com/economia/finanzas-y-negocios/2019/03/12/la-mitad-de-lasempresas-que-cotizan-en-la-bolsa-portena-no-tienen-ninguna-mujer-en-sus-directorios/. Acceso en: 14 jun. 2020

EMBID IRUJO, J. M., La promoción de la igualdad entre hombres y mujeres en la composición del consejo de administración de las sociedades mercantiles. In: AAVV. Situaciones de crisis en las sociedades comerciales, Ed. Ad Hoc, 2010

FERNÁNDEZ DE LA VEGA, M. T., El Derecho a la Igualdad Efectiva de Mujeres y Hombres. Aranzadi: Ed. Thomson Reuters, 2018.

GARCÍA DE ENTERRÍA, J., El reglamento del Consejo de Administración. In: Estudios de Derecho de sociedades y Derecho concursal. Libro homenaje al profesor Rafael García Villaverde. Vol I. Madrid: Ed. Marcial Pons, 2007.

HUERTA VIESCA, M. I., Las mujeres en la nueva regulación de los consejos de administración de las sociedades mercantiles españolas: (artículo 75 de la Ley orgánica $3 / 2007$, de 22 de marzo, para la igualdad efectiva de mujeres y hombres, Cizur Menor (Navarra), Aranzadi, 2009.

LEIÑENA MENDIZÁBAL, E La participación de la mujer en los Consejos de Administración de las Sociedades Corporativas. RDM, 278, 2010.

MÁRQUEZ LOBILLO, P., Consideraciones acerca de la incorporación de la mujer a los consejos de administración tras la Ley Orgánica de Igualdad, RdS, 32 (2009).

MERCADER UGUINA, J. R. (coord.), Comentarios laborales de la Ley de Igualdad entre Mujeres y Hombres. Valencia: Tirant lo Blanch, 2007

MONTENEGRO, Nadia E. La adecuada composición del órgano de administración en sociedades que hacen oferta pública de sus valores negociables (presentación oral). In: IV Congreso Argentino en Mercado de Capital - Seminarios de Aspectos Legales, Universidad del Cema, 16 ago. 2006.

LAGUILLO, Ana Belén Campuzano. La presencia equilibrada de hombres y mujeres en los consejos de administración de las sociedades mercantiles. In: UGUINA, Jesús R. Mercader. Comentarios laborales de la ley de igualdad entre mujeres y hombres. Valencia: Tirant lo Blanch, 2007, p. 435-452.

LANUS OCAMPO, María Cecília. Enfoque de género en el ámbito corporativo. La Ley, Buenos Aires, a. LXXXII, n. 240, 20 dic. 2018, pp. 13-14. Disponible en: ttps://www.thomsonreuters.com.ar/content/dam/openweb/documents/pdf/arg/whitepaper/suplemento_especial_genero_y_derecho-version2.pdf. Acceso en: 14 jun. 2020;

SENET VIDAL, M. J., Igualdad efectiva en la responsabilidad social de las empresas. In: El derecho a la Igualdad Efectiva de mujeres y hombres. Aranzadi: Ed. Thomson Reuters, 2018.

SEVILLA MERINO, J., El principio de presencia o composición equilibrada", en El derecho a la Igualdad Efectiva de mujeres y hombres. Aranzadi: Ed. Thomson Reuters, 2018.

UE - UNION EUROPEA. Plan de trabajo para la igualdad entre las mujeres y los hombres (2006-2010). Bruselas, UE, 2006. Disponible en: https://eur-lex.europa.eu/legalcontent/ES/TXT/?uri=LEGISSUM\%3Ac10404. Acceso en: 14 jun. 2020

Artigo recebido em: 06/12/2020.

Aceito para publicação em: 1410/08/2021. 